\title{
LA INFLUENCIA DEL DARWINISMO SOBRE LOS CONCEPTOS RACIALES EN MÉXICO
}

\author{
Fabiola Juárez-Barrera \\ Facultad de Estudios Superiores Zaragoza, Universidad Nacional Autónoma de México \\ Email: fabye_lucas@hotmail.com \\ ORCID iD: http://orcid.org/0000-0001-7190-0952 \\ A. Alfredo Bueno-Hernández \\ Facultad de Estudios Superiores Zaragoza, Universidad Nacional Autónoma de México \\ Email: abueno@unam.mx \\ ORCID iD: http://orcid.org/0000-0003-4663-9937
}

Recibido: 4 diciembre 2015; Aprobado: 27 septiembre 2016.

Cómo citar este artículo/Citation: Juárez-Barrera, Fabiola and Bueno Hernández, A. Alfredo (2017), "La influencia del darwinismo sobre los conceptos raciales en México", Asclepio, 69 (1): p174. doi: http://dx.doi.org/10.3989/asclepio.2017.06

RESUMEN: Se ha señalado reiteradamente que Vicente Riva Palacio y Andrés Molina Enríquez fueron influidos por las ideas de Darwin al desarrollar sus propios conceptos raciales sobre el mestizo mexicano. Sin embargo, después de analizar dichas ideas tanto en su contexto biológico original como en el ámbito social al que fueron trasplantadas, concluimos que tal afirmación solo puede aceptarse en un sentido laxo. Su tesis sobre la superioridad del mestizo se sustentó más en concepciones lineales de la evolución y en mixtificaciones propias que en el modelo darwinista de selección natural. Conocer las repercusiones del darwinismo fuera de su ámbito original contribuye a entender cómo se dio el complejo e inevitable interjuego entre ciencia, sociedad y política. Aunque la apropiación que hicieron Riva Palacio y Molina de las ideas darwinistas no tuvo rigor conceptual ni metodológico, contribuyó a la construcción ideológica del mestizo como una raza evolutivamente avanzada. Esta tesis contrasta con la que prevaleció en otros países latinoamericanos, donde se concibió al mestizo como la personificación de la degeneración racial.

PALABRAS CLAVE: Darwinismo; Darwinismo Social; Razas; Mestizo; México.

\section{THE INFLUENCE OF DARWINISM ON RACIAL CONCEPTS IN MEXICO}

ABSTRACT: It has been repeatedly pointed out that Vicente Riva Palacio and Andrés Molina Enríquez were influenced by Darwin's ideas to develop their own racial concepts regarding the Mexican half-blood. However, after analysing said ideas both in their original biological context as in the social context they were transferred to, it is concluded that this affirmation can only be accepted sensu lato. Their thesis about the superiority of the half-blood is more strongly based on lineal conceptions of evolution and their own alterations than in the Darwinist model of natural selection. It is important to know the influence of Darwinism outside its original context as it helps to understand how the complex and unavoidable exchanges among science, society and politics occurred. Their appropriation of the Darwinist ideas may not be conceptually or methodologically accurate, but it contributed to the ideological construction of the half-blood as an advanced race in terms of evolution. This thesis contrasts with the most prevailing one in other Latin American countries, where the half-bloods were perceived as the personification of a racial degeneration.

KEY WORDS: Darwinism; Social Darwinism; Races; "Mestizo"; Mexico.

Copyright: (C) 2017 CSIC. Este es un artículo de acceso abierto distribuido bajo los términos de la licencia Creative Commons Attribution (CC BY) España 3.0. 


\section{INTRODUCCIÓN}

Se han realizado diversos estudios de gran interés histórico tanto sobre las ideas raciales (Stabb, 1959; Aguirre, 1969; González-Navarro, 1988; Lomnitz, 1993; Stern, 2000; Gall, 2004) como sobre la introducción del darwinismo en diversos países de Latinoamérica (Genovés, 1959; Maldonado-Koerdell, 1959; Moreno de los Arcos, 1984; Ruiz, 1987; Glick, Ruiz y Puig-Samper, 1999a; Puig-Samper, Ruiz y Galera, 2002; Barahona, 2009). Aunque se ha señalado la influencia de las ideas evolucionistas sobre los conceptos raciales en México (Argueta y Ruiz, 2002, p. 342; Basave, 2002, p. 31), no se han analizado específicamente cuáles fueron las ideas darwinistas que retomaron para construir el nuevo proyecto de nación, en qué sentido se entienden en su contexto original y cómo se reinterpretaron al extrapolarlas al ámbito social. Se abordan en particular las ideas darwinistas a las que recurrieron Vicente Riva Palacio y Andrés Molina Enríquez para destacar las virtudes raciales de los mexicanos. Al final se hace una comparación sucinta entre las ideas raciales prevalecientes en México con las de otros países latinoamericanos y se exploran posibles causas de esas diferencias.

Las teorías sobre la evolución de Lamarck y Darwin, las tesis monogenista y poligenista sobre el origen de la especie humana, el determinismo hereditario y el racismo científico, proveyeron nociones que fueron empleadas por los intelectuales mexicanos en su afán por construir una identidad nacional que integrara al indígena al gran proyecto de la nueva nación.

\section{PRIMERAS EXPLICACIONES SOBRE LA DIVERSIDAD RACIAL}

A partir de la llustración se inició la investigación sistemática de las diferencias biológicas y culturales de los distintos pueblos. Ello significó un rompimiento con las ideas del influyente naturalista Carl von Linné (17071778), quien clasificó las razas humanas de acuerdo a sus características esenciales. La taxonomía linneana quedó en entredicho cuando se encontraron individuos que no armonizaban con los modelos tipológicos definidos como razas puras ni poseían los caracteres esenciales propios de cada una.

En la segunda mitad del siglo XVIII, Georges Louis Lecrerc, conde de Buffon (1707-1788) concluyó que la dispersión era la causa de que la especie humana se hubiera diferenciado geográficamente en razas debido a influencias climáticas, aunque todas habían derivado de la raza caucásica original (Lenoir, 1980, p. 82).
Buffon criticó duramente la clasificación esencialista de Linneo, a la cual juzgó como un mero artificio que no representaba al mundo real (Sloan, 1976, p. 359). Propuso un sistema natural alternativo basado en linajes históricos, es decir, en ancestros y descendientes relacionados genealógicamente. De este modo, las razas humanas se concibieron como entidades vinculadas por un ancestro común y no como entidades creadas de manera independiente con sus propios caracteres esenciales.

En resumen, ya desde las primeras explicaciones modernas sobre las razas humanas, se fijaron dos posturas, una genealógica y otra esencialista.

\section{RACISMO ‘CIENTÍFICO’}

Después de que la razón reemplazó a la revelación como medio legítimo de conocimiento, la antropología dio al término 'raza' una connotación científica fundada en conocimientos morfológicos y biogeográficos. Surgió entonces una ideología que pretendió fundamentar el racismo sobre criterios objetivos (Marks, 2008 , p. 1). Al inicio del siglo XIX, la antropología clásica y el filantropismo fueron perdiendo ímpetu en Europa ante el surgimiento del racismo científico. Según este nuevo enfoque, había diferencias innatas físicas, mentales y culturales entre las poblaciones humanas que dependían de la herencia y no de las condiciones ambientales. En consecuencia, los programas educativos para cristianizar y civilizar a los pueblos bárbaros resultaban no solo ingenuos sino vanos, pues su efecto sería irrelevante en la modificación de los rasgos hereditarios. Muchas de las teorizaciones del siglo XIX sobre las razas humanas aceptaron como un 'hecho' incontrovertible que había diferencias biológicas irreversibles entre las razas superiores e inferiores. En Estados Unidos, Samuel George Morton (1799-1851) se afanó en aportar evidencia empírica para afirmar la tesis de la desigualdad y los orígenes separados de las razas humanas (Gould, 1978), contraviniendo la creencia cristiana ortodoxa sobre el origen común de todos los hombres. Así, el poligenismo se convirtió en un componente ideológico central para los defensores de la desigualdad racial y del esclavismo.

El célebre naturalista suizo Louis Agassiz (18071873), quien emigró a los Estados Unidos en 1846 y se convirtió en uno de los padres fundadores de la ciencia en este país, terminó por acreditar la tesis poligénica de Morton. Agassiz retomó la tesis preadamita de Isaac de La Peyrère (Harris, 1982, p. 75). Sostuvo que los negros no descendían de la pareja primigenia del Génesis, ya que fisiológica y anató- 
micamente eran completamente diferentes de los blancos. Empleó el mismo argumento que había usado La Peyrère dos siglos atrás: suponer el origen de todas las razas humanas a partir de Adán y Eva era un error, pues en el propio Génesis se podía ver claramente que habían existido hombres anteriores a Adán (Agassiz, 1850, p. 184).

Con el prestigio de Agassiz, la ideología racista y la tesis poligénica quedaron sancionadas científicamente.

\section{EL MESTIZAJE COMO DEGENERACIÓN}

Agassiz sostuvo que los híbridos interraciales eran individuos degradados, pues perdían todas las características superiores de la raza blanca. Él mismo lo había atestiguado en Brasil, donde el mestizaje había dejado consecuencias sociales nefastas. Agassiz suscribió las ideas de Joseph Arthur de Gobineau (18161882), quien atribuyó la decadencia de las naciones europeas a la mezcla de las raza nórdica pura con las razas inferiores del sur (Gobineau, 1853-1855).

En contraste, Darwin refrendó el monogenismo (Darwin, 1859). Aunque antes de desarrollar sus ideas transformistas, el joven Darwin creía que la diferencia entre un hombre salvaje y uno civilizado era mayor que la que había entre un animal salvaje y uno domesticado, al final tuvo que reconocer que no había fundamento para creer que los esclavos negros o los fueguinos estuvieran más cercanos a los animales de lo que lo estaba él mismo (Darwin, 1871a, p. 232). El abismo que separaba al hombre de las bestias y a los fueguinos de los europeos no era sino una ilusión reconfortante.

El filósofo Herbert Spencer (1820-1903) hizo su propia interpretación de las ideas de Darwin para construir el llamado 'darwinismo social'. Describió a la selección natural como 'la supervivencia del más apto’ y popularizó una visión lineal y progresista de la evolución, con la raza blanca a la cabeza seguida por las demás razas, las cuales representaban estadios evolutivamente atrasados. La idea de la supervivencia del más apto encajó perfectamente con la noción popular del progreso, ampliamente aceptada entre los europeos del siglo XIX (Marks, 2008, p. 5). Spencer sostuvo como tesis central que la intervención del Estado debería limitarse exclusivamente a mantener el orden público y el respeto a la propiedad privada, permitiendo la libre actuación de las leyes naturales, que por sí solas, conducirían al progreso social.

Sin embargo, adoptó también la idea común sostenida por los transformistas, según la cual la evolución ocurría por caracteres adquiridos que eventualmente se convertían en hereditarios. Esta idea, al ser trasplantada al campo social, implicaba que la educación produciría cambios conductuales hereditarios mediante un proceso acumulativo y progresivo. La idea de que la naturaleza humana podía mejorarse mediante la educación en unas cuantas generaciones tuvo un atractivo tan grande que persistió muchos años, incluso después que los biólogos abandonaran la hipótesis de la herencia de caracteres adquiridos ante la falta de sustento empírico. Esta idea se convirtió en la filosofía de la esperanza, aunque los neolamarckistas sociales europeos y norteamericanos, incluido Spencer, se rehusaron a extender su optimismo a las razas no blancas (Bowler, 1989, pp. 296-298). Spencer no previó la contradicción en que caía al admitir el principio de herencia de caracteres adquiridos. ¿Por qué oponerse a las políticas benefactoras del Estado si éstas podían redimir de sus taras a los individuos menos dotados, incluidos los individuos de las razas de color? Intentó salir de este embrollo afirmando que en la lucha por la existencia, la herencia predominaba sobre el ambiente.

Aunque Darwin y Spencer compartieron la creencia en la herencia de caracteres adquiridos, hay una diferencia entre ellos con implicaciones raciales importantes. Mientras que Darwin concibió la evolución como un proceso ramificado, Spencer la entendió como un proceso lineal, en donde las razas no blancas habían quedado evolutivamente rezagadas. Incluso surgió una versión evolucionista poligenista, que aunque aceptaba que todas las razas humanas procedían de un ancestro común, afirmaba que la divergencia entre ellas había sido tan amplia que ya se habían transformado en especies diferentes (Wolpoff y Caspari, 2013, p. 325). Bajo esta visión, el principio malthusiano de competencia despiadada se convirtió en el motor del progreso social y la mejora de la civilización. Pronto, la 'darwinización' de la sociedad fue una empresa boyante.

\section{CONCEPTOS RACIALES EN EL MÉXICO INDEPENDIENTE}

Después de la lucha independentista, surgió en México el ideal de construir un nacionalismo propio. Las élites gobernantes decidieron que el mundo indígena debía ser transformado para poder integrarse al nuevo proyecto de nación. Tanto liberales como conservadores, que "en el fondo eran ... más afines que contrarios" (García y Vieyra, 1996, p. 146), se interesaron por construir esquemas sobre la nueva nación. Entre los conservadores, Francisco Pimentel, conocedor tanto de los trabajos craneométricos de Petrus 
Camper como de los de Morton, reivindicó al indio mexicano revirtiendo los propios argumentos de esos autores. Afirmó que el indio tenía la misma capacidad craneal e intelectual de las razas europeas (Pimentel, 1864 , p. 212). Entre los liberales, Ignacio Ramírez señalaba que el blanqueamiento y la homogenización racial eran ideales ilusorios en una nación compuesta por multitud de pueblos, cada uno con su propia lengua, por lo que el reconocimiento de la diversidad racial y lingüística era la condición para el nuevo proyecto de nación (Ramírez, 1889, p. 191).

Más allá de estas primeras ideas tomadas de la historia natural, fue hasta el final de la década de 1870 cuando algunas ideas provenientes de la biología entraron plenamente en la discusión sobre los pueblos indígenas de México. Las teorías de Lamarck y de Darwin, las tesis mono y poligenista así como la teoría sobre la degeneración racial y su contraparte, el vigor mestizo, se discutieron en los círculos intelectuales. A partir de estos debates, algunos personajes de la intelligentsia mexicana adaptaron esas ideas a una visión progresista del mestizaje, convirtiéndolas en elementos centrales del discurso que elaboraron sobre la nueva nación.

Al cobijo del régimen de Porfirio Díaz, los 'científicos', mayoritariamente positivistas, usaron la ciencia para legitimar su ideología. Al adoptar las ideas positivistas de Comte, los 'científicos' quedaban comprometidos, al menos teóricamente, con la idea de que las diferencias raciales no estaban relacionadas con cualidades intelectuales ni morales hereditarias, sino con avances o retardos relativos de evolución social. Podía haber razas atrasadas, pero no fatalmente inferiores. Comte rechazó la idea de que existiera una secuencia lineal de inferioridad a superioridad entre las razas. Aunque cada una tenía un rasgo distintivo (la raza blanca era la más inteligente, la amarilla la más trabajadora y la negra la más sentimental), se complementaban entre sí y la dominancia de alguna era relativa, pues había variado a lo largo de la historia. Las diferencias entre razas desaparecerían eventualmente con el advenimiento de la sociedad científica y la concurrencia de todas era necesaria para el camino adecuado de la humanidad hacia el progreso (Todorov, 2003, pp. 51-52).

\section{INTERPRETACIONES EVOLUCIONISTAS DE VICENTE RIVA PALACIO}

Vicente Riva Palacio fue un personaje de vasta cultura. Liberal, militar, político y naturalista aficionado, pero sobre todo literato, cuando el término 'literatu- ra' se refería a todo aquello digno de escribirse, ya fuera sobre política, economía, leyes, ciencia, y por supuesto, también a las bellas letras (Ortiz-Monasterio, 2012, p. 23). Desde sus inicios como escritor, Riva Palacio entendió con toda claridad que el elemento central de la nueva nación mexicana era necesariamente el mestizaje.

Fue director de la monumental obra México a través de los Siglos y autor del segundo volumen. En éste retomó algunas de las ideas expuestas por Darwin en la edición francesa de The Descent of Man (Moreno, $1984,20)$ para desarrollar una explicación original sobre la superioridad evolutiva de la raza india. Después de analizarla de acuerdo a "los fríos y descarnados axiomas de la filosofía zoológica y á las doctrinas de la joven pero robusta ciencia de la antropología" (Riva Palacio, 1888, p. 471), concluyó que era una raza superior, pues estaba: ..."en un período de perfección y progreso corporal, superior al de todas las otras razas conocidas..." (Riva Palacio, 1888, p. 472).

Según Riva Palacio, es el carácter lampiño de los indios lo que revela su adelanto evolutivo. Darwin ciertamente había llamado la atención sobre el carácter lampiño de los indios americanos (Darwin, $1871 b$, p. 321), aunque no juzgó tal condición como un indicio de progreso. Esta idea es un agregado de Riva Palacio, quien afirma que la posesión de pelo ha sido considerada por casi todos los naturalistas modernos como un carácter inútil e incluso perjudicial, sobre todo para los hombres que habitan las zonas tropicales, pues el pelo es el lugar donde los parásitos encuentran abrigo. Argumenta además que su ausencia no puede considerarse como un carácter adquirido por el hábito continuado de arrancarlos, pues tanto los romanos como los australianos, que sí acostumbraban quitarse el pelo, no se habían vuelto lampiños. Esta condición se debía por tanto a la selección natural e indicaba que los indios americanos habían evolucionado como una raza pura desde la prehistoria.

Llama la atención que Riva Palacio omita la opinión del propio Darwin sobre este asunto, quien a su vez citó a Thomas Belt como el autor de la tesis de que la ausencia de pelo en los indígenas americanos era un carácter adaptativo porque los libraba de parásitos. En realidad Darwin, en la segunda edición de The descent of man (Darwin, 1874, p. 57), agregó un argumento que no aparece en la edición original de 1871 y que invalidaba la tesis de Belt, aduciendo que con o sin pelo, ninguno de los cuadrúpedos tropicales habían podido finalmente librarse de los parási- 
tos. El naturalista inglés no veía ventaja ni desventaja adaptativa alguna en la condición lampiña o peluda, como tampoco en las barbas, los labios gruesos o los grandes pechos. Estos caracteres no podían explicarse por acción de la selección natural, sino por la selección sexual, a la cual Darwin le dio gran importancia en The Descent of Man. Ya desde la primera edición de On the Origin of Species, Darwin, al referirse a las marcadas diferencias entre las razas humanas, había escrito: "I may add that some little light can apparently be thrown on the origin of these differences, chiefly through sexual selection of a particular kind, [...]" (Darwin, 1859, p. 199). No era la naturaleza la que seleccionaba estos caracteres, sino los propios individuos en el juego del apareamiento (Desmond y Moore, 1994, pp. 544-545).

Riva Palacio recurrió también al principio de correlación expuesto por Darwin en The Descent of Man (Darwin, 1871a, p. 151). Con base en este principio, Riva Palacio conjeturó audazmente que la falta de barba en los indios se compensaba con la posesión de una dentadura perfecta que conservaban hasta edad avanzada. Mientras que para Darwin el principio de correlación explicaba la presencia de estructuras que no eran por sí mismas adaptativas, para Riva Palacio generaba solo características adaptativas en los indios. De acuerdo con Darwin, en el hombre civilizado las muelas del juicio se habían vuelto rudimentarias (Darwin, 1874, p. 20) y los caninos habían perdido su carácter de arma ofensiva para adquirir una función masticatoria (Darwin, 1874, p. 40). Vale señalar que para Darwin, esta tendencia se aplicaba de manera general a toda la especie humana. Sin embargo, Riva Palacio la asumió como particularidad exclusiva de la raza india, sin evidencia empírica que lo respaldara y como una evidencia adicional a favor de que en los indios había ocurrido "una evolución progresiva superior a la de las razas europeas y africanas" (Riva Palacio, 1888, p. 474), las cuales mantenían todavía vestigios de caninos y muelas del juicio. Cita la hipótesis del descubridor del hombre de Neanderthal, Hermann Schaaffhausen, quien afirmaba que en las razas más civilizadas, la parte posterior dentaria de la mandíbula era siempre reducida debido a que se nutrían con alimentos ablandados por el cocimiento y cita también los estudios del médico Juan Francisco López, quien después de examinar indios que habitaban los poblados de Huamantla y Tepoztlán, encontró en todos ellos sin excepción la sustitución de caninos por molares y la ausencia de muela del juicio. Al referirse a la dentición de los indios americanos, Riva Palacio concluyó lo siguiente:

\begin{abstract}
“...las razas americanas son autóctonas y en un grado de progreso superior al de las otras razas, pues si por progreso debe entenderse la acumulación de los caracteres que en un organismo son útiles y necesarios para sostener la lucha por la existencia, y la desaparición más ó menos completa de los inútiles y perjudiciales poseídos por anteriores generaciones, es indudable que los indios estaban en una evolución más avanzada, pues conservando en estado ya rudimentario los mismos órganos que en estado rudimentario tienen los individuos de las otras razas, como las mamilas en el sexo masculino, habían perdido la barba y el pelo en el cuerpo, la muela del juicio, y adquirido un molar nuevo, sustituyendo al canino que en las razas más avanzadas en Europa todavía subsiste en estado rudimentario." (Riva Palacio, 1888, p. 476).
\end{abstract}

Se ha señalado que Riva Palacio cayó en contradicciones al adentrarse "en el pantanoso terreno de la genética" (Basave, 2002, p. 31), pues aunque por un lado destacó los caracteres de evolución avanzada de los indios, por otro afirmó que éstos carecían absolutamente de "preponderancia de transmisión" (Riva Palacio, 1888, p. 472), de modo que al final, las ventajas evolutivas de los indígenas terminarían por perderse en el cruzamiento. En realidad, Riva Palacio no se adentró en la genética, y no lo podría haber hecho, pues esta disciplina empezó a desarrollarse sobre bases experimentales solo hasta el inicio del siglo XX, cuando los trabajos de Mendel fueron redescubiertos simultáneamente por Hugo de Vries, Carl Correns y Erick Tchermark (Ruiz y Ayala, 2002, p. 106). Riva Palacio solo expresó creencias populares relacionadas con la herencia, comunes en su tiempo.

\section{INTERPRETACIONES EVOLUCIONISTAS DE ANDRÉS MOLINA ENRÍQUEZ}

Otro estudioso del tema racial durante el Porfiriato fue Andrés Molina Enríquez (1868-1940), un reconocido abogado, sociólogo y etnógrafo de ideología positivista. En 1909 publicó un estudio titulado Los grandes problemas nacionales, donde abordó la desventaja que representaba una población mexicana disgregada y dispersa en el territorio nacional. Molina sostuvo que la mejor solución para este problema era el mestizaje, pues el mestizo conjugaría lo mejor de la herencia española e indígena (Sámano-Rentería, 2004, p. 142).

Es claro que Molina no recurrió al modelo darwinista para el desarrollo de su mestizofilia. Como bien se ha señalado (Basave, 2002, pp. 85-86), la explicación 'científica' que desarrolló para ese propósito, en un 
tiempo en que la 'cientificidad' era parte importante de la ideología vanguardista, se basó en el evolucionismo social spenceriano, según el cual las sociedades humanas evolucionarían hacia un orden cada vez mayor. Sin embargo, en su intento, terminó percatándose que se había enredado en una contradicción flagrante, ya que el mismo Spencer había expresado que el mestizo mexicano era un desadaptado, incapaz de adecuarse tanto a la cultura materna como a la paterna, según lo demostraba el hecho de que México, compuesto mayoritariamente por mestizos, era un país enfrascado en permanentes luchas y revoluciones (Basave, 2002, p. 92). Este juicio de Spencer minaba en su núcleo la tesis mestizófila de Molina. Sin embargo, a contrapelo del desprecio expresado por Spencer sobre los mexicanos, Molina no los excluyó del progreso evolutivo.

La disyuntiva entre raza y cultura provocó contradicciones en el pensamiento de Molina. Por un lado, se opuso a la idea común del blanqueamiento indiscriminado como estrategia para mejorar la sangre india. Resultaba absurdo permitir la entrada de agricultores blancos improvisados que no conocían el clima ni los sistemas de cultivo más adecuados (Molina, 1909, p. 239). En este caso, resulta claro que Molina antepone la cultura a la raza. La mera condición racial de los europeos era insuficiente para mejorar las condiciones del campo mexicano. Sin embargo, por otro lado, Molina persistió en su tesis principal: la raza era el elemento determinante, por lo que había que fundir a todas las razas que habitaban México en una sola, bajo la delirante premisa de que el mestizo conjugaría los mejor de cada una.

Como apoyo a esta idea preconcebida, Molina retomó la interpretación que había hecho Riva Palacio de las ideas expuestas por Darwin en The Descent of Man. Al argumento morfológico sobre la superioridad del indio agregó otro cultural: desde antes de la conquista, los pueblos indígenas habían alcanzado un alto nivel de cultura, equiparable al de las naciones civilizadas de Europa. Hizo además una distinción conceptual entre evolución y selección que intentaba resolver la contradicción de Riva Palacio y explicaba por qué en el mestizo prevalecían los caracteres de la raza india sobre los de la blanca:

“... si las razas blancas podían considerarse superiores á las indígenas por la mayor eficacia de su acción, consecuencia lógica de su más adelantada evolución, las razas indígenas podían considerarse como superiores á las razas blancas por la mayor eficacia de su resistencia, consecuencia lógica de su más adelantada selección" (Molina, 1909, pp. 257-258).

\begin{abstract}
"Creemos, pues, tener razón al afirmar que las razas de más adelantada evolución, tienen más acción, que las razas de más adelantada selección, tienen más resistencia... En el choque de dos razas rara vez deja de producirse la mezcla de ellas, y en el producto intermedio, a nuestro juicio, domina, como lo indica el Sr. Riva Palacio, la sangre de la raza más resistente" (Molina, 1909, p. 262).
\end{abstract}

Con base en esta distinción conceptual entre selección y evolución, Molina concluye que la raza mestiza es la más fuerte y la más poderosa desde el punto de vista biológico. Sin embargo, es claro que estos conceptos novedosos que introduce Molina no provienen de Darwin. No hay ni en El Origen de las Especies ni en La Descendencia del Hombre ninguna alusión al respecto.

Es clara también la influencia que ejerce en él el evolucionismo de Ernst Haeckel. No podría haber sido más claro el divorcio de Molina con el modelo darwinista que cuando alude a la 'fuerza formatriz interna' y a la dialéctica entre ésta y las fuerzas externas como la explicación científica de la variación y evolución orgánica (Molina, 1909, pp. 34, 272, 273). Darwin se apegó con todo propósito a los mejores cánones metodológicos de su tiempo. Su compromiso con el modelo de explicación de la vera causa (Martínez, 2001; Guillaumin, 2001) explica el cuidado especial que tuvo en evitar recurrir a entelequias metafísicas tales como los impulsos internos lamarckistas o las fuerzas formatrices haeckelianas. Tampoco propuso Darwin un modelo teleológico ni lineal de la evolución. Las especies se van modificando ramificadamente, según el cambio en las circunstancias, sin un propósito ni una meta prefijada.

\section{MESTIZOFILIA Y MESTIZOFOBIA EN LATINOAMÉRICA}

Durante el auge del racismo científico prevaleció como categoría de análisis social la identidad racial sobre la cultural. La idea de la superioridad de la raza blanca fue común entre los naturalistas europeos y norteamericanos, independientemente de sus orientaciones teóricas. El surgimiento del evolucionismo se usó para afianzar el discurso determinista, sobre todo en una de sus versiones, que era al mismo tiempo poligenista y racista (Stocking, 1973, p. Ixx). Los evolucionistas, ya fueran monogenistas o poligenistas, darwinianos o spencerianos, coincidieron en concebir a la raza blanca como la raza superior. Tal concepción encierra incluso una especie de calvinismo científico (Suárez, 2005, p. 64), donde unas razas estarían predestinadas a la salvación, esta vez no espiritual, sino 
evolutiva, mientras que otras estarían condenadas al fracaso biológico y a la extinción. Surgió entonces una curiosa asimetría en la literatura anglosajona: mientras que para explicar la superioridad de la raza blanca se usó la filosofía optimista del progreso de Spencer, se recurrió a la filosofía de la desesperanza de Gobineau para condenar a las razas mezcladas.

En los países latinoamericanos se hicieron valoraciones contrastantes del mestizo, tanto a favor como en contra. Se ha dicho que en las naciones latinoamericanas con una población indígena mayoritaria, como México, Bolivia y Perú, se apostó a favor del mestizaje como proceso de cohesión social, mientras que en países predominantemente criollos como Argentina y Uruguay, ocurrió lo contrario (Argueta y Ruiz, 2002, p. 342). Algunos casos parecen apoyar esta generalización. Por ejemplo, una de las versiones más virulenta de la indiofobia la expresó José Ingenieros, quien sostuvo que Argentina era una nación grande porque estaba "liberada de las razas inferiores" (Fuentes, 2002, p. 8). Lo que llama la atención es que Ingenieros tuvo la misma influencia spenceriana que Molina, aunque no tuvo necesidad de mixtificarla como éste, para llegar a conclusiones diametralmente opuestas.

También hubo casos que apoyan la tesis aludida en países con población mestiza mayoritaria. En Brasil, Euclides da Cunha en los inicios del siglo XX, y décadas después Gilberto Freyre, apostaron por el mestizo como el elemento central de la nacionalidad brasileña (Basave, 2002, pp. 103-104). Sin embargo, todavía en el siglo XIX, Brasil seguía siendo un país predominantemente esclavista y las élites gobernantes, principalmente de ascendencia europea, vieron a la composición multiétnica como el principal obstáculo para su progreso. La comunidad médica estableció las bases de una estricta política de estratificación social, la cual tasaba a los individuos de acuerdo a su grado de mestizaje: entre menos blancos, menos valían (SánchezArteaga, 2009, pp. 69-72). El médico Joao Batista de Lacerda (1846-1915), inspirado en el poligenismo de Agassiz, afirmó que América era un centro de creación independiente y que los indios americanos eran una especie separada de la raza blanca (Bertol y Romero, 1999, p. 90), pues la anatomía comparada revelaba que el blanco estaba tan separado de los negros como de los monos catarrinos (Sánchez-Arteaga, 2009, p. 98). Los tres híbridos principales descritos por Agassiz ${ }^{1}$ se consideraron como el vívido y lamentable contraste de las virtudes de los individuos de raza blanca. Si ya de por sí las ideas de Gobineau y Agassiz habían permeado en la intelectualidad brasileña, la influencia de la antropología craneométrica de Paul de Broca (Bertol y Romero, 1999, p. 88) terminó por reafirmar una fuerte corriente racista en este país sudamericano, a pesar del notable incremento de la población mestiza.

En Perú, con una población mestiza también muy grande, José de la Riva Agüero propuso al inicio del siglo XX, que el mestizo debía ser la base de la nacionalidad peruana, aunque sin mucha convicción, pues solo sostuvo esta postura en los inicios de su carrera política, cuando se declaraba como agnóstico positivista y anticlerical. Tiempo después cambió radicalmente hacia una posición claramente fascista, alabando incluso abiertamente a Francisco Franco como la encarnación de sus ideales (Villarías-Robles, 1998, pp. 41-42).

Sin embargo, en la dinámica de las sociedades humanas no operan las relaciones simples. Hubo otros países latinoamericanos en los cuales predominó el desprecio por los mestizos a pesar de su abundancia, como Bolivia, donde se empleó el reduccionismo biológico de forma directa y sin modificaciones locales para elaborar una teoría científica de la desigualdad. Las élites gobernantes adoptaron la línea del evolucionismo social desarrollado en Europa con sus categorías darwinianas de lucha por la existencia y supervivencia del más apto para implementar una política discriminatoria contra indígenas y mestizos. Alcides Arguedas publicó su célebre libro Pueblo Enfermo en 1909 , donde expuso la tesis de la degeneración racial del mestizo de la zona andina (Urías, 1996, pp. 102104) como causa del retraso del país (Basave, 2002, p. 104). El primer introductor del darwinismo científico en Bolivia, el médico y polígrafo Belisario Díaz Romero, profesaba abiertamente un racismo poligenista (Argueta y Ruiz, 2002, p. 339).

En Chile, con gran inmigración blanca y poca población indígena, primero se vio al mestizo, bautizado popularmente como el 'roto', de manera despectiva (Gutiérrez, 2010, pp. 134-135). Sin embargo, al iniciar el siglo XX, el médico Nicolás Palacios (1854-1911) inventó el mito del roto, reivindicado ahora como el representante de una raza híbrida única y superior, sublimada por la noble mezcla de las sangres araucana y gótica (Basave, 2002, p. 104), muy distinta a la sangre de los otros híbridos latinoamericanos. En su estudio, que más que sociológico puede entenderse como una saga mítica (Alvarado-Borgoño, 2004, p. 3), Palacios elabora una mestizofilia peculiarmente contradictoria, pues aunque ensalza la mezcla de sangres, al mismo tiempo se muestra ferozmente xenofóbico, oponiéndose a la inmigración de latinos a Chile, a los 
cuales veía como evolutivamente desadaptados y como un elemento que podría descomponer esa mezcla supuestamente extraordinaria (Gutiérrez, 2010, p. 126). Así, con la pura fuerza de su imaginación, Palacios revirtió el desprecio por el mestizo chileno desde una postura claramente racista.

De lo anterior se desprende que las posturas mestizófilas y mestizófobas que se desarrollaron en las naciones latinoamericanas fueron independientes de que tuvieran poblaciones mayoritariamente blancas o mestizas. La interpretación de las ideas darwinistas en favor del mestizo, como en el caso de México, o en su contra, como en Brasil, (Sánchez-Arteaga 2009, p. 97), Argentina y Bolivia (Glick, Ruiz y PuigSamper, 1999b, pp. 13-15), no tuvo rigor conceptual. Para construir una nacionalidad propia, se inventó una sustancia unitaria, ya fuera el mestizo, el blanco o el roto, y se vinculó a una unidad sociopolítica (Williams, 1995, p. 232). La historia muestra que las ideologías de raza y nación frecuentemente se intersectaron, lo mismo en Latinoamérica que en Europa o Nueva Zelanda (Wade, 2001, pp. 845-846). Sin embargo, ese afán común por construir un nacionalismo propio que independizara a los países latinoamericanos de Europa, nació con una contradicción interna, pues el concepto mismo de nacionalismo había sido importado de Europa (Ramos, 1951, p. 86).

\section{CONCLUSIONES}

Llama la atención que en el México decimonónico, las ideas poligenistas de Gobineau, Agassiz y Broca, así como su asociación entre mestizaje y degeneración, no parecen haber tenido mayor trascendencia, a pesar de que el gobierno de Porfirio Díaz se caracterizó por un marcado clasismo, donde los fuertes sobrevivían y los débiles tenían que irse (Katz y Lomnitz, 2011, p. 25). Dos condiciones parecen haber influido sobre las posturas en pro del mestizo. La primera fue el reciente pasado liberal de la nación, que favoreció el avance social de los mestizos. Ya desde 1855, Benito Juárez había promulgado una ley que declaraba iguales a todos los individuos ante la ley y la sociedad. Juárez mismo, un indio zapoteco, llegó a ocupar la presidencia de la república y su sucesor, Porfirio Díaz, a pesar de sus pretensiones afrancesadas, era un mestizo oaxaqueño.

La segunda condición que contuvo al racismo entre los intelectuales mexicanos fue la idea comteana de la igualdad racial y la determinación del desarrollo del individuo por las condiciones sociales y no por las raciales. La abrumadora influencia que tuvo el positivis- mo entre los intelectuales mexicanos no solo se opuso al darwinismo (Glick, Ruiz y Puig-Samper, 1999b, p. 12), sino también a una de sus derivaciones, como lo fue el determinismo biológico rampante. La idea de la superioridad racial blanca entraba en conflicto directo con los postulados positivistas. Los positivistas mexicanos reprimieron las posiciones spencerianas a ultranza, en donde las razas evolutivamente superiores terminarían por desplazar inexorablemente a las inferiores. Ello permite entender que en México surgiera sin mayor oposición la idea del mestizo como heredero de la resistencia evolutiva del indio.

La nota distintiva del biologicismo mexicano, fue recurrir directamente a conceptos del darwinismo biológico, a diferencia de las vertientes prevalecientes en otros países latinoamericanos que se nutrieron del darwinismo social, el cual a pesar de su denominación, tuvo tan poca influencia del darwinismo biológico. Tanto Riva Palacio como Molina Enríquez tomaron directamente de Darwin: 1) el principio de selección, 2) el principio de correlación de caracteres heredados y 3) la pérdida de rasgos vestigiales para sustentar la tesis del progreso evolutivo de los indígenas mexicanos y el vigor de los mestizos.

Sin embargo, conviene precisar que solo en un sentido muy laxo podría afirmarse que Riva y Molina se basaron en ideas de Darwin para sustentar su tesis sobre la superioridad del mestizo. Un análisis más puntual de esta relación revela que, de entrada, el conocimiento que tuvieron estos autores sobre la obra de Darwin no fue precisamente amplia, lo cual es muy comprensible, pues no se dedicaron al estudio de la historia natural. Lo que deja ver Riva, es que conoció las versiones al francés de La Descendencia del Hombre (Riva, 1888, pp. $430,473,474)$ y De la Variación de los Animales y las Plantas en el Estado Doméstico (Riva, 1888, pp. 474, 477), aunque no cita El Origen de las Especies. De Molina puede decirse que sí cita El Origen de las Especies (Molina, 1909, pp. 35, 286), aunque solo para referirse al principio de selección en un sentido muy general. Cita también La Descendencia del Hombre (Molina, 1909, p. $149,252,256)$, aunque solo porque transcribe los argumentos de Riva (Molina, 1909, pp. 48-56). Nótese que la afirmación de Riva sobre el carácter adaptativo de la condición lampiña no es de Darwin, quien lo explicó como producto de selección sexual, sino de Belt.

Donde sí hay un desprendimiento total de las ideas de Darwin es en los conceptos de acción-resistencia y evolución-selección que introduce Molina y que son ajenos a la obra de Darwin. Molina se formó en el evolucionismo spenceriano y comteano, que aprendió a 
través de Gabino Barreda (Labastida, 1986, p. xii). De allí y no de la influencia de Darwin, se explica su concepción lineal y teleológica de la evolución.

Así, el interés principal tanto de Riva como de Molina, cuando transladaron las ideas Darwin al plano social no fue el rigor conceptual, sino que simplemente las utilizaron como un recurso retórico para construir su mestizofilia. Por su parte, Molina transfirió sin ningún sustento empírico las supuestas ventajas de la raza india a la mestiza, que preservaba además las características de una selección muy avanzada. En esa etapa de su pensamiento, cuando se inclinaba más por la raza que por la cultura, Molina concluyó que aunque la raza indígena y la mestiza no se distinguían por su hermosura, su cultura o por los refinamientos propios de las razas de muy adelantada evolución, destacaban por su incomparable adaptación al medio y por su portentosa fuerza animal (Stabb, 1959, p. 408).

Mediante un notable malabarismo conceptual, Molina desarrolló su tesis mestizófila ia partir de autores claramente mestizófobos, como Spencer, Gumplowicz, Haeckel y Reclus! Sin embargo, terminó por percatarse de esta flagrante contradicción, e intentó resolverla regresando al enfoque no biologizante de Comte, suscribiendo ahora la tesis de que no había sociedades atrasadas o adelantadas, sino tan solo diferentes. Señaló que el error fundamental del evolucionismo era el concepto de que todos los grupos humanos estaban fatalmente destinados a recorrer el mismo camino lineal para alcanzar el progreso evolutivo. Adoptó entonces el relativismo cultural de Franz Boas, de acuerdo al cual el desarrollo social de los distintos pueblos no estaba determinado por sus características raciales, sino por su historia (Basave, 2002, p. 97). Con este giro radical, terminó por desechar las ideas darwinistas, a las que anteriormente había dado tanta importancia y por rechazar un racismo científico que se había convertido en un paradigma que pocos se atrevían a desafiar. Lo que ahora destaca Molina es el mestizaje cultural sobre el racial:

“... al irse formando los mestizajes, con elementos de las razas de que se derivan, han ido formando, por la lenta modificación de los elementos de la cultura respectiva de dichas razas, su propio modo de ser cultural. Si como parece que va sucediendo, dichos mestizajes llegan a formar una nacionalidad, esa nacionalidad lo será, tanto por la fuerza vital de sus unidades, cuanto por la originalidad, ponderación y refinamiento de las manifestaciones de su actividad, de su sentimiento, y de su espíritu." (Molina, 1986, pp. 129-130).
¿Qué queda al final de ese trasiego entre lo biológico y lo social, entre la raza y la cultura que inició Riva Palacio y desarrolló Molina? Los conceptos del vigor mestizo y del progreso evolutivo de los indígenas y mestizos mexicanos que desarrollaron son, por su originalidad, otro caso más que refuta el modelo simplista del difusionismo de la ciencia (Basalla, 1967). A partir de ellos, la exaltación del mestizo terminó por convertirse en una tradición inventada (Hobsbawn y Ranger, 2012) de gran influencia en México ${ }^{2}$, promovida vigorosamente por los gobiernos postrevolucionarios. Sin embargo, no hubo ningún intento posterior por buscar algún sustento biológico al pretendido progreso evolutivo del indígena mexicano ni a la afirmación de que esta raza había sufrido una selección más intensa. No obstante, los conceptos de Riva Palacio y Molina tuvieron una consecuencia social notable. Mientras que en otros países se intentó alcanzar la unidad nacional mediante la pureza racial, en México se intentó precisamente al contrario, es decir, mediante la mezcla de razas (Aguirre, 1969, p. 64). Nosotros añadiríamos que irónicamente, al final ambas iniciativas no fueron más que meras invenciones retóricas.

Finalmente convendría hacer notar que la interpretación del entonces novedoso concepto de progreso evolutivo que hicieron Riva Palacio y Molina Enríquez destaca por su tono de actualidad. A diferencia de una corriente importante que interpretó al progreso en un sentido predeterminado y teleológico, ellos se apegaron a su sentido original darwiniano, es decir, lo entendieron en un sentido básicamente utilitario, como un mero proceso de adaptación a condiciones concretas y desligado de cualquier dirección metafísica. No imaginaron que la idea que concibe al progreso como un resultado programado de la evolución sería cada vez más cuestionada ni que el concepto mismo de progreso se convertiría en uno de los puntos más polémicos y recurrentes de la teoría evolutiva, desde ese entonces hasta la actualidad.

\section{AGRADECIMIENTOS}

Este trabajo derivó del apoyo del Proyecto PAPIIT UNAM 401110 “Creacionismo y Darwinismo: El debate sobre la distribución geográfica de los organismos desde On the Origin of Species (Darwin, 1859) hasta Climate and Evolution (Matthew, 1915)", financiado por la Dirección General de Asuntos del Personal Académico de la Universidad Nacional Autónoma de México.

Agradecemos a David Espinosa Organista y Carlos Pérez Malváez la revisión crítica del borrador. 


\section{NOTAS}

1 Estos tres híbridos eran los mulatos, resultantes de la cruza entre blancos y negras, los mamelucos, producto de la cruza de blancos con indias, y los cafuzos, que surgían de la cruza entre individuos de la raza india y negra. Nótese el sexismo implícito, pues se da por entendido que en los dos primeros casos, las cruzas son entre varones blancos con hembras de las otras razas, mientras que en el caso de los cafuzos, era indistinto que se cruzaran varones o hembras de las razas india y negra (Agassiz, Louis (1868), A Journey in Brazil, Boston, Ticknor and Fields, p. 297, [en línea], doi: http://dx.doi.org/10.5962/bhl.title.85962

\section{BIBLIOGRAFÍA}

Agassiz, Louis (1850), "Geographical Distribution of Animals", Christian Examiner and Religious Miscellany, 48, pp. 181204, [en línea], disponible en: http://people.wku.edu/ charles.smith/biogeog/AGAS1850.htm, [consultado el 8/02/2015].

Aguirre, Gonzalo (1969), “Oposición de raza y cultura en el pensamiento antropológico mexicano", Revista Mexicana de Sociología, 31 (1), pp. 51-71.

Alvarado-Borgoño, Miguel (2004), "La modernidad maldita de Nicolás Palacios: Apuntes sobre Raza Chilena", Gaceta de Antropología, 20, pp. 1-9, [en línea], disponible en: http:// hdl.handle.net/10481/7276. [consultado el 24/05/2015].

Argueta, Arturo y Ruiz, Rosaura (2002), "Darwin en Bolivia y México". En: Puig-Samper, Miguel Ángel; Ruiz, Rosaura y Galera, Andrés (eds.), Evolucionismo y cultura. Darwinismo en Europa e Iberoamérica, Madrid, Junta de Extremadura, Universidad Nacional Autónoma de México, Ediciones Doce Calles, pp. 332-352.

Barahona, Ana (2009), "La introducción del darwinismo en México", Teorema, XXVIII, pp. 201-214.

Basalla, George (1967), "The spread of Western science", Science, 156 (3775), pp. 611-622, [en línea], doi: http://dx.doi. org/10.1126/science.156.3775.611

Basave, Agustín (2002), México Mestizo. Análisis del nacionalismo mexicano en torno a la mestizofilia de Andrés Molina Enríquez, México, Fondo de Cultura Económica.

Bertol, Heloisa y Romero, Magali (1999), "La introducción del darwinismo en Brasil: las controversias de su introducción". En: Glick, Thomas F.; Ruiz, Rosaura y Puig-Samper, Miguel Ángel (eds.), El darwinismo en España e Iberoamérica, Madrid, Universidad Nacional Autónoma de México, Consejo Superior de Investigaciones Científicas y Ediciones Doce Calles, pp. 83-102.

Bowler, Peter John (1989), Evolution. The History of an Idea, Berkeley, University of California Press, pp. 296-298.
2 En La raza cósmica, José Vasconcelos llevó la tesis de la superioridad de la raza latinoamericana a la categoría de un verdadero mito esotérico, si se permite el oxímoron (Vasconcelos, José (1925), La raza cósmica. Misión de la raza iberoamericana. Notas de viajes a la América del sur, Madrid, Agencia Mundial de Librería, [en línea], disponible en: http://www.filosofia.org/aut/001/razacos.htm, [consultado el 07/04/2015].

Darwin, Charles (1859), On the origin of species by means of natural selection, London, John Murray, pp. 85-86, 199, [en línea], disponible en: http://darwin-online.org.uk/converted/pdf/1859_Origin_F373.pdf, [consultado el 18/03/2015].

Darwin, Charles (1871a), The descent of man and selection in relation to sex, Vol. I, London, John Murray, [en línea], disponible en: http://darwin-online.org.uk/converted/pdf/1871_ Descent_F942.1.pdf, [consultado el 25/05/2015].

Darwin, Charles (1871b), The descent of man and selection in relation to sex, Vol. II, London, John Murray, [en línea], disponible en: http://darwin-online.org.uk/converted/ pdf/1871_Descent_F942.2.pdf, [consultado el 25/05/2015].

Darwin, Charles (1874), The descent of man and selection in reIation to sex, London, John Murray, [en línea], doi: http:// dx.doi.org/10.5962/bhl.title.54341

Desmond, Adrian y Moore, James (1994), Darwin. The Life of a Tormented Evolutionist, New York, Norton, pp. 544-545.

Fuentes, Carlos (2002), "Prólogo". En: Basave, Agustín, México mestizo. Análisis del nacionalismo mexicano en torno a la mestizofilia de Andrés Molina Enriquez, México, Fondo de Cultura Económica, pp. 7-11.

Gall, Olivia (2004), “Identidad, exclusión y racismo: reflexiones teóricas y sobre México", Revista Mexicana de Sociología, 66 (2), pp. 221-259, [en línea], doi: http://dx.doi.org/10.2307/3541457

García, Alejandro y Vieyra, Lilia (1996), “México a través de los siglos: revisión crítica", Boletín, Instituto de Investigaciones Bibliográficas, I (2), pp. 145-158.

Genovés, Santiago (1959), "Darwin y la antropología”, Revista de la Sociedad Mexicana de Historia Natural, XX (I-IV), pp. 31-41.

Glick, Thomas F., Ruiz, Rosaura y Puig-Samper, Miguel Ángel (eds.) (1999a), El darwinismo en España e Iberoamérica, Madrid, Ediciones Doce Calles, pp. 13-15.

Glick, Thomas F., Ruiz, Rosaura y Puig-Samper, Miguel Ángel (1999b), "Introducción". En: Glick, Thomas F.; Ruiz, Rosaura 
y Puig-Samper, Miguel Ángel (eds.), El darwinismo en España e Iberoamérica, Madrid, Ediciones Doce Calles, pp. 11-16.

Gobineau, Arthur (1853-1855), Essai sur l'innégalité des races humaines, Paris, Libraire de Firmin Didot Frères.

González-Navarro, Moisés (1988), "Las ideas raciales de los científicos, 1890-1910", Historia Mexicana, XXXVII (4), pp. 565-583.

Gould, Stephen Jay (1978), “Morton's Ranking of Races by Cranial Capacity”, Science, 200 (4341), pp. 503-509.

Guillaumin, Godfrey (2001), “El desarrollo de la metodología de la vera causa en el siglo XIX. En: Barahona, Ana; Suárez, Edna y Martínez, Sergio (eds.), Filosofía e Historia de la Biología, México, Universidad Nacional Autónoma de México, pp. 133-154. En: Barahona, Ana; Suárez y S. Martínez (eds). Filosofía e Historia de la Biología. Universidad Nacional Autónoma de México. México, D.F. pp. 133-154.

Gutiérrez, Horacio (2010), “Exaltación del mestizo: la invención del roto chileno", Universum, 1 (25), pp. 122-139, [en línea], doi: http://dx.doi.org/10.4067/S0718-23762010000100009

Harris, Marvin (1982), El Desarrollo de la Teoría Antropológica. Historia de las Teorías de la Cultura, Madrid, Siglo XXI.

Hobsbawn, Eric y Ranger, Terence (eds.) (2012 [1983]), The Invention of Tradition, Cambridge, Cambridge University Press, [en línea], doi: http://dx.doi.org/10.1017/ CBO9781107295636

Katz, Friedrich y Lomnitz, Claudio (2011), El Porfiriato y la Revolución en la Historia de México, México, Era.

Labastida Muñoz, Horacio (1986), "Prólogo". En: Molina Enríquez, Andrés, La Revolución Agraria de México, México, UNAM y Miguel Ángel Porrúa, pp. xi-xxxiv.

Lenoir, Timothy (1980), "Kant, Blumenbach, and vital materialism in German biology", Isis, 256, pp. 77-108.

Lomnitz, Claudio (1993), “Hacia una antropología de la nacionalidad mexicana", Revista Mexicana de Sociología, 55 (2), pp. 169-195, [en línea], doi: http://dx.doi.org/10.2307/3541108

Maldonado-Koerdell, Manuel (1959), “Linneus, Darwin y Wallace en la bibliografía de ciencias naturales. I. Primeras referencias a sus ideas en México", Revista de la Sociedad Mexicana de Historia Natural, XX (1-4), pp. 63-78.

Marks, Jonathan (2008), "Scientific racism, history of". En: Moore, John Hartwell (ed.), Encyclopedia of Race and Racism, Vol. 3, London, MacMillan, pp. 1-16.

Martínez, Sergio F. (2001), “El mecanismo de la selección natural: Su origen y su papel en discusiones metodológicas en la segunda mitad del siglo XIX". En: Barahona, Ana; Suárez, Edna y Martínez, Sergio (eds.), Filosofía e Historia de la Biología, México, Universidad Nacional Autónoma de México, pp. 225-279.
Molina Enríquez, Andrés (1909), Los Grandes Problemas Nacionales, México, Carranza e Hijos, [en línea], disponible en: http://biblio.juridicas.unam.mx/libros/6/2603/1.pdf, [consultado el 12/02/2015].

Molina Enríquez, Andrés (1986) [1932], La Revolución Agraria de México. 1910-1920, Tomo I, México, Coordinación de Humanidades y Miguel Ángel Porrúa.

Moreno de los Arcos, Roberto (1984), La polémica del darwinismo en México: Siglo XIX, México, Universidad Nacional Autónoma de México.

Ortiz-Monasterio, José (2012), “Prólogo”. En: Riva Palacio, Vicente, Vicente Riva Palacio, México, Cal y Arena, pp. 11-63.

Pimentel, Francisco (1864), Memoria sobre las causas que han originado la situación actual de la raza indígena de México y medios de remediarla, México, Imprenta de Andrade y Escalante, [en línea], disponible en: https://archive.org/details/ memoriasobrelas00pimegoog

Puig-Samper, Miguel Ángel, Ruiz, Rosaura y Galera, Andrés (eds.) (2002), Evolucionismo y cultura. Darwinismo en Europa e Iberoamérica, Madrid, Junta de Extremadura, Universidad Nacional Autónoma de México, Ediciones Doce Calles.

Ramírez, Ignacio (1889), Obras de Ignacio Ramírez, Tomo I, México, Oficina Tipográfica de la Secretaría de Fomento, [en línea], disponible en: https://archive.org/details/obrasdeignacior00altagoog, [consultado el 23/03/2015].

Ramos, Samuel (1951), El perfil del hombre y la cultura en México, Madrid, Espasa Calpe, p. 86, [en línea], disponible en: https://zoonpolitikonmx.files.wordpress.com/2012/07/ samuel-ramos-el-perfil-del-hombre-y-la-cultura-en-mexico. pdf, [consultado el 12/08/2015].

Riva Palacio, Vicente (1888), México a Través de los Siglos, Tomo II, Barcelona, Espasa y Compañía, [en línea], disponible en: https://archive.org/details/mexicotravsdeloss02riva, [consultado el 09/01/2015]

Ruiz, Rosaura (1987), Positivismo y Evolución: Introducción del Darwinismo en México, México, Universidad Nacional Autónoma de México.

Ruiz, Rosaura y Ayala, Francisco (2002), De Darwin al DNA y el origen de la humanidad: la evolución y sus polémicas, México, Universidad Nacional Autónoma de México y Fondo de Cultura Económica.

Sámano-Rentería, Miguel Ángel (2004), "El indigenismo institucionalizado en México (1936-2000): un análisis”. En: Ordóñez-Cifuentes, José Emilio (ed.), La construcción del Estado nacional: democracia, justicia, paz y Estado de derecho, México, Universidad Nacional Autónoma de México, pp. 141-158.

Sánchez-Arteaga, Juan Manuel (2009), “Las ciencias y las razas en Brasil hacia 1900", Asclepio, LXI (2), pp. 67-100, [en línea], doi: http://dx.doi.org/10.3989/asclepio.2009.v61.i2.285 
Sloan, Phillip Reid (1976), "The Buffon - Linnaeus Controversy", Isis, 67 (3), pp. 356-375, [en línea], doi: http://dx.doi. org/10.1086/351629

Stabb, Martin S. (1959), "Indigenism and racism in Mexican thought: 1857-1911", Journal of Inter-American Studies, 1 (4), pp. 405-423, [en línea], doi: http://dx.doi. org/10.2307/165117

Stern, Alexandra (2000), "Mestizofilia, biotipología y eugenesia en el México posrevolucionario: Hacia una historia de la ciencia y el Estado, 1920-1960", Relaciones, 81 (21), pp. 5991, [en línea], disponible en: http://www.redalyc.org/articulo.oa?id=13708104, [consultado el 15/12/2014].

Stocking, George W. (1973), From chronology to ethnology. James Cowles Prichard in British Anthropology, 1800-1850, Chicago, University of Chicago Press.

Suárez y López Guazo, Laura (2005), Eugenesia y racismo en México, México, Universidad Nacional Autónoma de México.

Todorov, Tzvetan (2003), Nosotros y los otros, México, Siglo XX.

Urías Horcasitas, Beatriz (1996), "El determinismo biológico en México: del darwinismo social a la sociología criminal", Re- vista Mexicana de Sociología, 58 (4), pp. 99-126, [en línea], doi: http://dx.doi.org/10.2307/3541043

Villarías-Robles, Juan J. (1998), “El intelectual liberal vuelto fascista: el caso de José de la Riva-Agüero y el fascismo peruano". En: Huertas, Rafael y Ortiz, Carmen (eds.), Ciencia y fascismo, Madrid, Ediciones Doce Calles, pp. 41-60, [en línea], disponible en: http://hdl.handle.net/10261/45601, [consultado el 02/04/2015].

Wade, Peter (2001), "Racial Identity and Nationalism: A Theoretical View from Latin America", Ethnic and Racial Studies, 24, pp. 845-865, pp. 845-846, [en línea], doi: http://dx.doi. org/10.1080/01419870120064007

Williams, Brackette F. (1995), "Classification systems revisited: Kinship, caste, race and nationality as the flow of blood and the spread of rights". En: Yanagisako, Sylvia y Delaney, Carol (eds.), Naturalizing Power: Essays in Feminist Cultural Analysis, New York, Routledge, pp. 201-236.

Wolpoff, Milford. H. y Caspari, Rachel (2013), “Paleoanthropology and Race". En: Begun, David R. (ed.), A Companion to Paleoanthropology, West Sussex, WileyBlackwell, pp. 321-337, [en línea], doi: http://dx.doi. org/10.1002/9781118332344.ch17 